\title{
Co-exposure of cannabinoids with amphetamines and biological, behavioural and health outcomes: a scoping review of animal and human studies
}

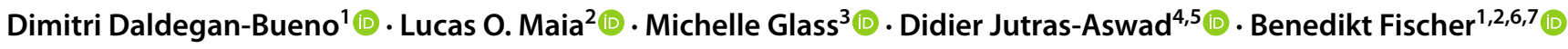

Received: 1 March 2021 / Accepted: 2 August 2021 / Published online: 6 October 2021

(C) The Author(s) 2021

\begin{abstract}
Rationale The growing prevalence of psychostimulant (including amphetamine) use and associated health harms, with limited treatment options, present a global challenge. There is an increasing availability and medical applications of cannabinoids, and growing interest in their therapeutic potential for addictive disorders.

Objectives The objective of this study is to review available data regarding cannabis/cannabinoid co-use or exposure on amphetamine-related outcomes.

Methods Towards the present scoping review, we systematically searched four databases (Medline, Web-of-Science, CINAHL Plus and PsycInfo) using cannabis/cannabinoid and amphetamine text-terms identifying peer-reviewed, Englishlanguage studies published in 2000-2020 involving multiple methods approaches among both human and animal study samples, assessing the association of co-use/administration of cannabis/cannabinoids products with non-medical amphetamines on biological, behavioural or health outcomes.

Results Twenty-five articles were included. Pre-clinical studies $(n=15)$ found mostly protective effects of single or repeated cannabinoids administration on rodents in amphetamine addiction models, amphetamine-induced models of human mental disorders (e.g. schizophrenia) and amphetamine-induced neurotoxicity. Human studies $(n=10)$ were more heterogeneously designed (e.g. cross-sectional, case-control, longitudinal) and assessed natural ongoing cannabis and methamphetamine use or dependence, showing mostly enhanced harms in a diversity of outcomes (e.g. mental health, methamphetamine use, cognition). Conclusions While human studies suggest cannabis use as an adverse risk factor among non-medical amphetamine users, pre-clinical studies suggest therapeutic potential of cannabinoids, especially cannabidiol, to alleviate amphetamine addiction and harms, including treatment outcomes. Given increasing psychostimulant harms but lack of care options, rigorous, high-quality design studies should aim to translate and investigate pre-clinical study results for potential therapeutic benefits of cannabinoids for amphetamine use/abuse in human subjects.
\end{abstract}

Keywords Amphetamines · Cannabis · Cannabinoids · Cannabidiol · Co-use · Exposure · Tetrahydrocannabinol · Translational research $\cdot$ Addictive behaviour $\cdot$ Review

\section{Introduction}

A $0.5 \%$ (approximately 27 million people) of the world's adult population use amphetamines, a central nervous system stimulant. Of these users, approximately 6.6 million

This article belongs to a Special Issue on Cannabis and

Cannabinoids

Benedikt Fischer

bfischer@sfu.ca

Extended author information available on the last page of the article
(86/100,000 population) are estimated to be dependent, rendering amphetamine substances to be among the most used illicit drugs globally (Degenhardt et al. 2013; Peacock et al. 2018; UNODC 2020). Extra-medical amphetamine use, especially methamphetamine (a more potent structural form (Lake and Quirk 1984)), is associated with elevated risks for both mortality and morbidity outcomes, including acute poisoning, mental health (e.g. depression, psychosis, suicidal behaviours) and neurocognitive impairments, cardiovascular problems, injury and violence (Cumming et al. 2020; Marshall and Werb 2010; Marshall et al. 2011; McKetin et al. 2019; Wood et al. 2006). Amphetamine dependence 
was responsible for about $0.6 \%$ (approximately 326,000 deaths) of global all-cause mortality in 2017 , entailing a mortality risk among people with amphetamine dependence up to six times higher than the general population (Farrell et al. 2019). Changes in illegal drug production patterns suggest that amphetamines supply and use have been globally increasing. Global methamphetamine seizures increased by $16 \%$ in 2015/16; despite seizures occurring mainly in North America and Asia, a 50\% increase of countries reporting seizures has been observed in the last decade. The majority $(90 \%)$ of dismantled methamphetamine laboratories are located in North America, with the USA harbouring most of these $(3,036$ or $82 \%)$ worldwide in 2017 - mostly supplying the local market (i.e. "kitchen lab") in contrast with large-scale, export-oriented laboratories in Mexico and East/ South-East Asia (Farrell et al. 2019; UNODC 2020).

Currently, there are no pharmacotherapeutic options approved for the treatment of stimulant use disorder, including amphetamines, at any of the main stages of treatment (e.g. withdrawal, relapse prevention) (Brandt et al. 2020; Castells et al. 2016; Morley et al. 2017; Pérez-Mañá et al. 2013; Ronsley et al. 2020; Siefried et al. 2020; Tardelli et al. 2020). The range of evidence-based, non-pharmacotherapeutic treatment or targeted prevention measures is overall highly limited, although select cognitive-behavioural interventions, including contingency management approaches, have shown some promise (Cumming et al. 2016; Fischer et al. 2015a; Knapp et al. 2007; Lee and Rawson 2008; Minozzi et al. 2016; Shearer 2007). This situation underscores a need for the examination of potentially effective therapeutic strategies or interventions for psychostimulant and specifically problematic amphetamine use or use disorders (Fischer et al. 2015b; Kogan and Mechoulam 2007; Shorter et al. 2015). Recently, there has been increased focus on the endocannabinoid system as a possible target for treating drug dependence, craving or withdrawal (Chye et al. 2019; Manzanares et al. 2018; Parsons and Hurd 2015; Spanagel 2020), with a growing number of studies examining the therapeutic effects of cannabinoid agents for addictive disorders (Batalla et al. 2019; Calpe-López et al. 2019; Prud'homme et al. 2015; Turna et al. 2019).

The endocannabinoid system (ECS) is a central biological system composed of at least two endocannabinoids (neurotransmitters; anandamide and 2-arachidoyl glycerol) that bind to cannabinoid receptors expressed throughout the mammalian vertebrate central and peripheral nervous systems. The ECS is centrally involved in regulating essential neural, physiological and cognitive processes, including movement control and motor coordination, learning and memory, mood, stress response and motivation, the immune system, appetite, addictive behaviours and pain modulation, among others (Cabral et al. 2015; Kruk-Slomka et al. 2017; Lu and Mackie 2021; Mechoulam and Parker 2013). The
ECS is also involved in key brain structures (e.g. prefrontal, limbic, striatal) and neurotransmitter systems (e.g. serotonin, dopamine) essential in the reward system and drug addiction. Of special interest is the role of CB1 receptors, expressed in brain regions involved in decision-making, withdrawal and relapse, and therefore, essential for modulating the rewarding effects of drugs (Chye et al. 2019; Maldonado et al. 2006; Manzanares et al. 2018; Parsons and Hurd 2015; Spanagel 2020). Moreover, there is increasing evidence and practice of medical usage for some indications (e.g. neuropathic pain, chemotherapy-induced nausea - for reviews see (Abrams 2018; Crippa et al. 2018; NASEM 2017)) and legal availability of cannabinoids products in many countries. Related, a purified cannabis-derived prescription form of cannabinoid has been recently approved in Europe and the USA for selected medical usage indications (GlobeNewswire 2020, 2021; Marcu 2020). Possibly beneficial effects or properties from cannabinoids agents specifically for addictive behaviours related to various substance groups (e.g. opioids, alcohol, nicotine, other stimulants) have been suggested, but no conclusive (e.g. clinical trialbased) evidence or reviews for amphetamine use and related problems presently exist (Abrams 2018; Prud'homme et al. 2015). On this basis, we sought to comprehensively review the existing, multidisciplinary studies and outcome data that have investigated the associations of cannabinoid exposure on amphetamine use and adverse outcomes in different study populations.

\section{Methods}

\section{Study aim and scope}

We conducted a scoping review which aimed to identify and summarize data on possible associations of natural or experimental co-administration of cannabinoids on amphetamine use-related biological, behavioural or health outcomes from different methodological or disciplinary approaches (e.g. pre-clinical, human experimental, observational studies). Cannabinoids were defined to include all-natural cannabis product forms or compositions (e.g. cannabidiol [CBD], tetrahydrocannabinol [THC]) and amphetamine products referred to both amphetamines and the structurally similar methamphetamines. Both cannabinoids and amphetamines were considered irrespective of way of use (e.g. smoke, oral ingestion) or user status (e.g. dependence); while cannabis was considered regardless of the intended purpose of use (e.g. medical, non-medical); only extra-medical use of amphetamines was considered. Considering the over-time evolution in amphetamine-type drug use, types of cannabis products available and the fact that the potential of cannabinoids for addiction-related outcomes has only been 
investigated more recently (Fischer et al. 2015b), we limited our search to studies published since 2000 with a goal of providing a comprehensive review of relatively recent studies and data.

\section{Search strategy}

The systematic search strategy applied was originally developed for MEDLINE through an iterative process by the co-authors; the final search strategy was revised and adjusted using the Peer Review Electronic Search Strategies (PRESS) checklist (McGowan et al. 2016) and translated to other databases. Four databases were accessed: MEDLINE (PubMed), Web of Science (core collection), CINAHL plus and PsycInfo. The search strategy focused on related cannabis/cannabinoid and amphetamine text words based on MeSH indexing terms (e.g. marijuana, cannabis, CBD, THC, amphetamine, methamphetamine). Given the broad scope and high heterogeneity/interdisciplinarity of study data specifically for outcomes comprised by our scoping review and the intent to comprehensively capture and document these, we did not limit the search by specific outcome terms to avoid a potential restriction, or loss of relevant studies or data. Rather, we left the search for, and identification of, any relevant outcomes as defined by the scope of the review to the subsequent title/abstract and content screening. The full strategy details are presented as supplementary material. Complementary search strategies included comprehensive hand-searching of the reference lists of included studies. The results from the multiple databases were collated and deduplicated using the Systematic Review Assistant-Deduplication Module (SRA-DM) (Rathbone et al. 2015) and then uploaded to Endnote (v.X9.2), where all screening management tasks were performed.

\section{Study screening and selection}

Study screening and selection were based on the following inclusion criteria: (1) original articles based on primary study data; (2) studies examining the direct/immediate, recent (i.e. prior 3 months in humans or same life-phase in animals [e.g. adults, adolescents]), or lifetime (of active users) co-use or co-exposure of cannabinoid products with amphetamine products in human or animal populations; (3) reporting biological, behavioural or health-related measures or outcomes (e.g. brain activity/function, craving, drug use/dependence); (4) with measures or outcomes available that somehow comparatively attributed to amphetamineonly use or groups versus amphetamine and cannabinoid co-use or co-exposure; and (5) in English-language studies published since 2000 to 28 October 2020. Following deduplication, titles and abstracts were screened by one lead reviewer (DDB), with potentially unclear or ambiguous cases identified and arbitrated towards consensus together with a second reviewer (BF), followed by full-text review of studies identified for possible inclusion by the same procedure. We excluded studies that did not meet the above criteria, as well as reviews, commentaries, case reports and case-control studies that mixed amphetamine- or cannabinoid-related data with other non-target drug use in study groups. To assess the eligibility of case-control studies for inclusion, we verified the exclusive presence of data for amphetamine use with/without cannabinoid use groups and attributable outcomes through information from the studies' methods and results sections. Abstracts or full studies excluded predominantly did not match the content- or outcome-specific criteria for the review (e.g. no clear cannabis/ amphetamine comparison, no current cannabis use) or could not be accessed. The attached flowchart (Fig. 1) presents the main process steps for the present review.

\section{Data presentation}

Given the aim of a comprehensive, scoping review comprising evidence from multi-disciplinary perspectives, both quantitative and qualitative types of studies in different population/samples (e.g. animal, human experimental, treatment, community) were included. For results documentation, we used a descriptive approach, inductively grouping studies principally by type of basic study population and methods/approach, further dividing into study sub-cluster, and narratively summarizing the essential study scope, measures and results. As is common for a scoping review, no risk of bias or quality assessment (Arksey and O'Malley 2005) and no meta-analyses (also due to the heterogeneity of study designs and outcomes) were conducted.

\section{Results}

\section{Characteristics of included studies}

Overall, 6,705 article citations were identified from the database searches which, after deduplication, resulted in a total of 3,237 potentially relevant abstracts that were screened. From these, 48 abstracts were selected for full-text review, with the final 25 articles included in the present review (Fig. 1). Eighteen (>70\%) of the studies were published 2010 onward. Articles broadly ranged across animal-based experimental models $(n=15)$ and human population $(n=10)$ studies. Animal studies involved rodents (rats or mice) experiments of THC or CBD (single or repeat) administration compared to controls (i.e. vehicle administration). On the basis of the data, studies were divided into three clusters: non-contingent models of addiction (e.g. conditioned place preference and sensitization experiments) $(n=6)$, contingent 


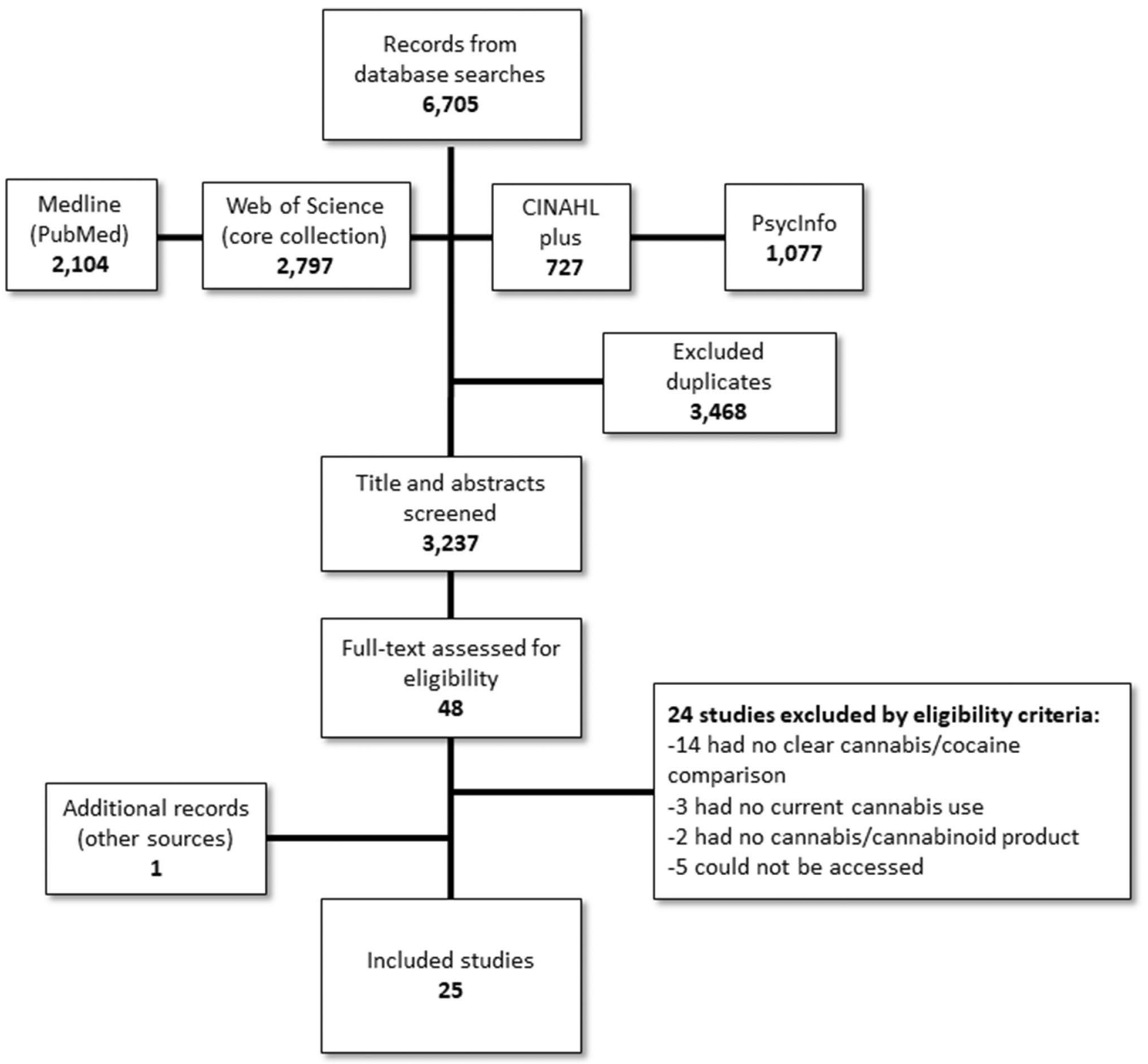

Fig. 1 Flowchart of the selection process of studies.

models of addiction (drug self-administration experiments) $(n=3)$ and amphetamine-induced human mental health models and neurotoxicity experiments $(n=6)$. Human population studies comprised methamphetamine and cannabis users or dependents within small or larger population sample. Study designs were cross-sectional (e.g. case-control, experimental intervention), prospective and longitudinal with biological, psycho-behavioural and mental health- or addiction-related outcomes, organized into three topical study clusters: brain structure/metabolism $(n=3)$, neuropsychological function or psychopathology symptoms $(n=3)$ and methamphetamine use patterns $(n=4)$. See Tables 1 and 2 for animal and human studies summaries.

\section{Pre-clinical studies in animals}

\section{Non-contingent models of addiction $(n=6)$}

Four vehicle-controlled studies investigated the effects of single CBD or THC administration in rats with an amphetamine- or methamphetamine-conditioned place preference (i.e. preference to a drug-paired environment) on amphetamine-reinstatement (i.e. return of drug-seeking after extinction of drug-seeking behaviour) and neurobiological outcomes. THC $(0.5 \mathrm{mg} / \mathrm{kg}$, i.p.) or CBD $(5 \mathrm{mg} / \mathrm{kg}$, i.p. $)$ administration $30 \mathrm{~min}$ before amphetamine place preference extinction trials ( $n=8-12 /$ group) potentiated the extinction 


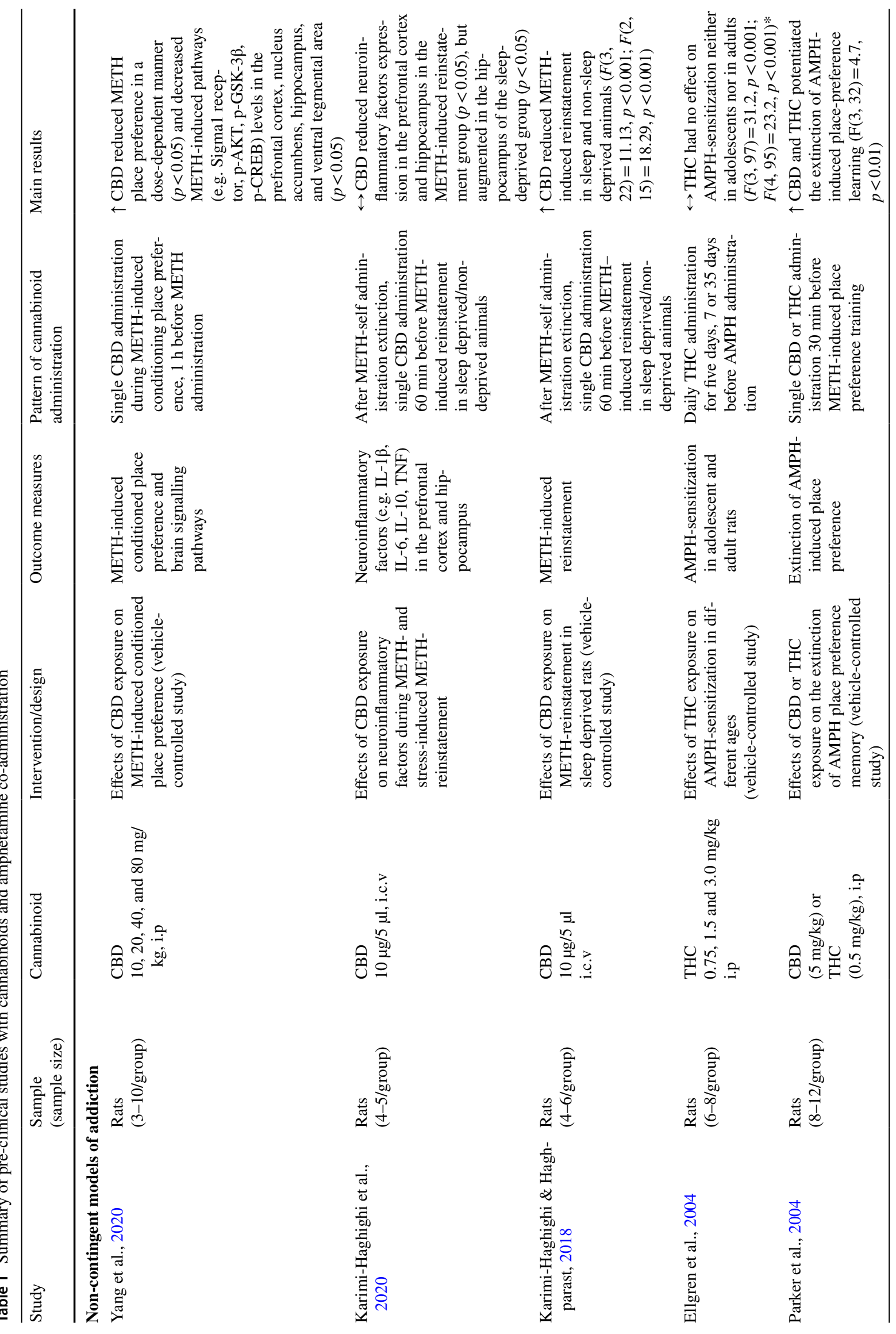




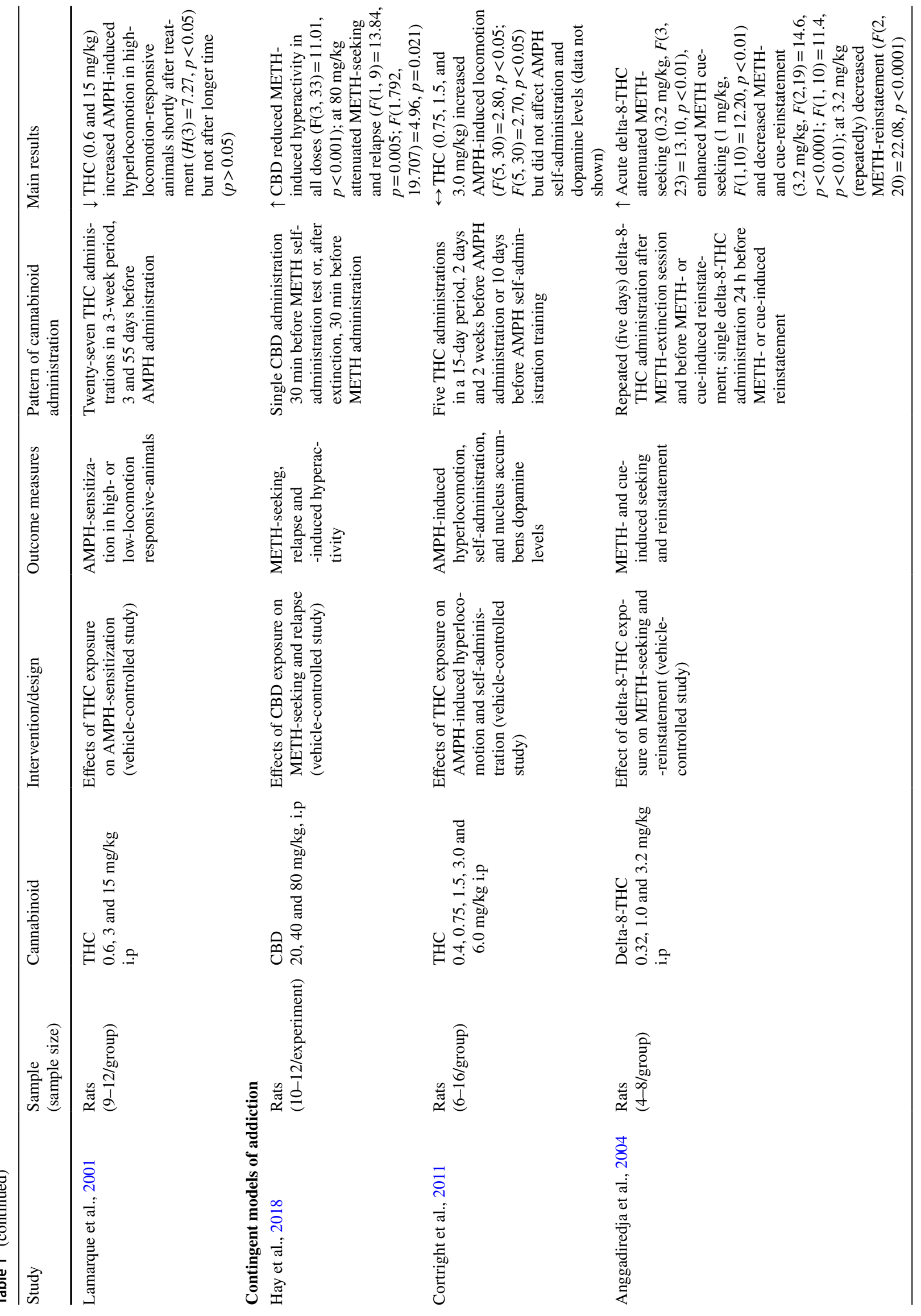




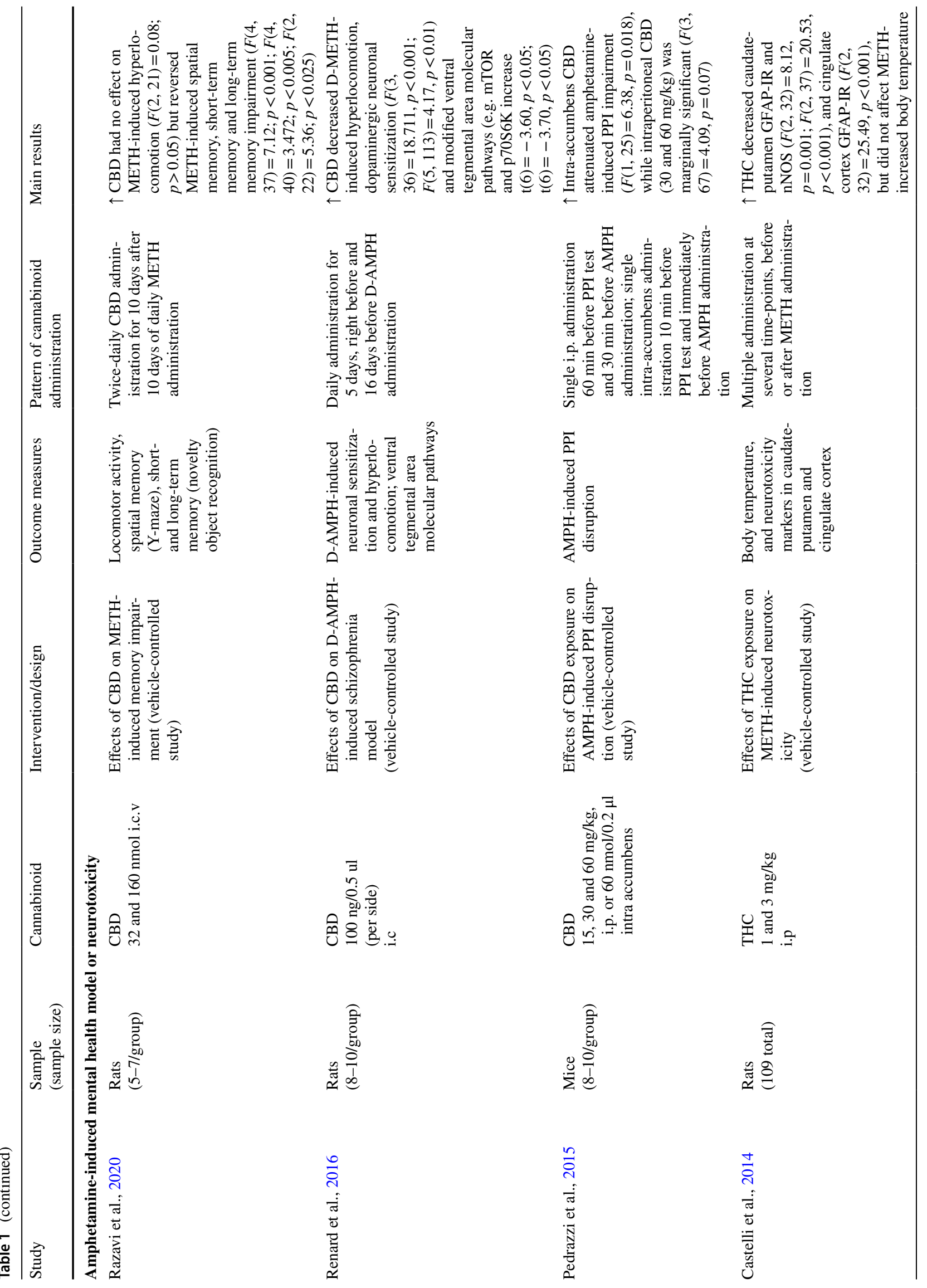




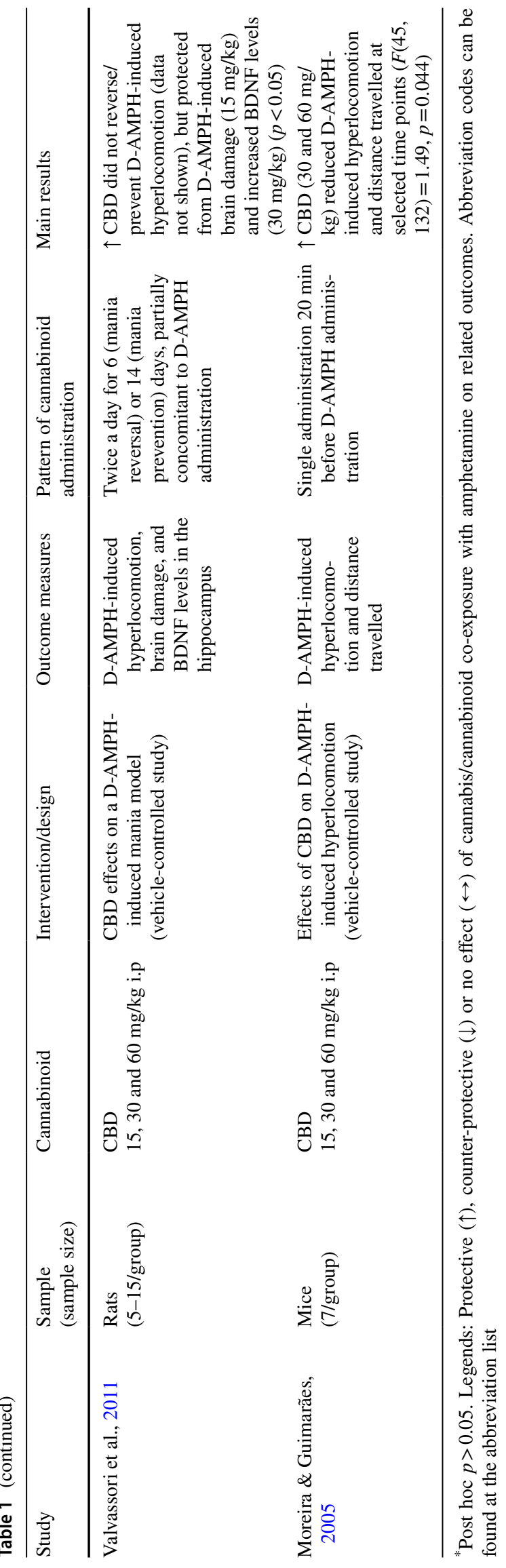




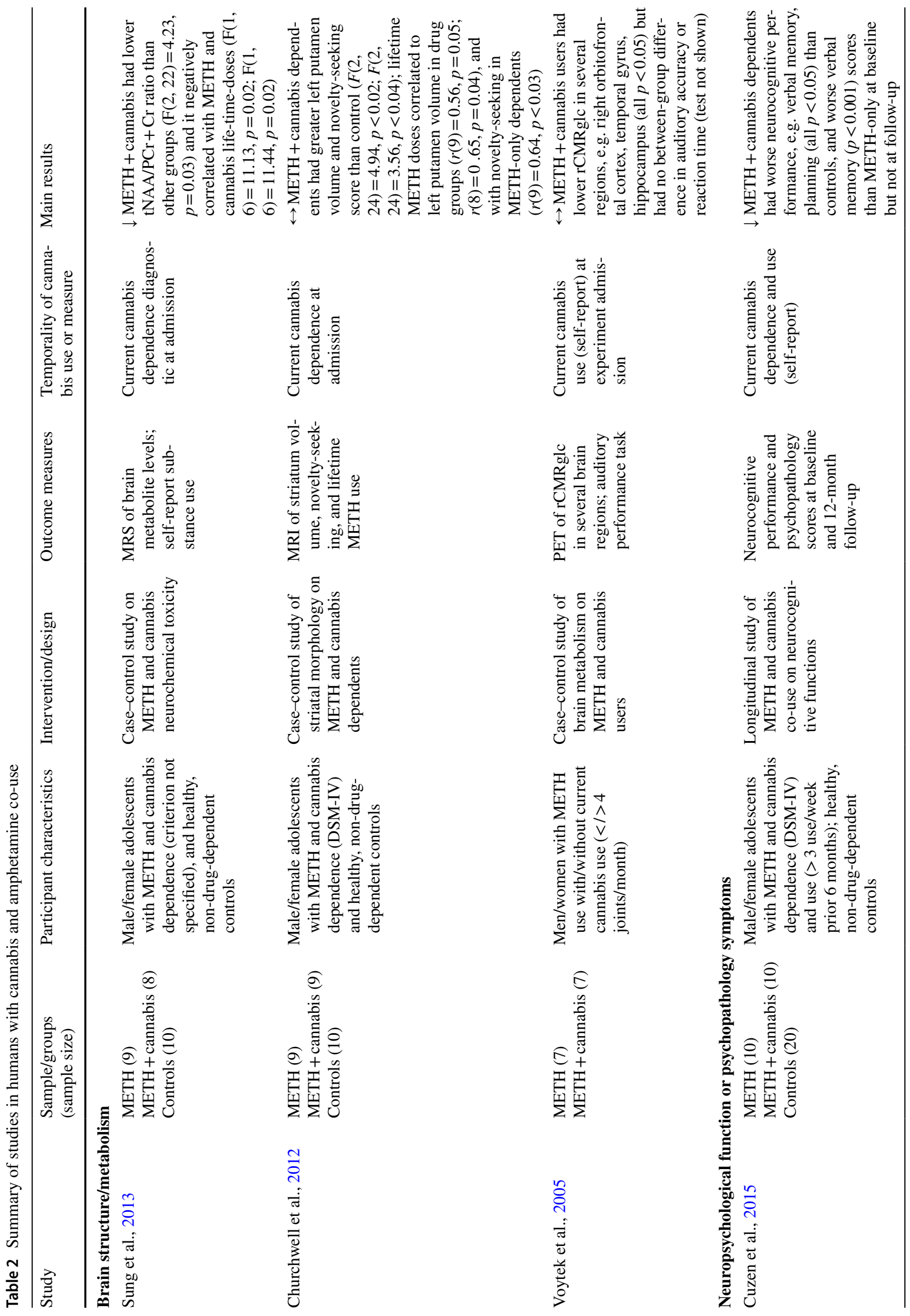




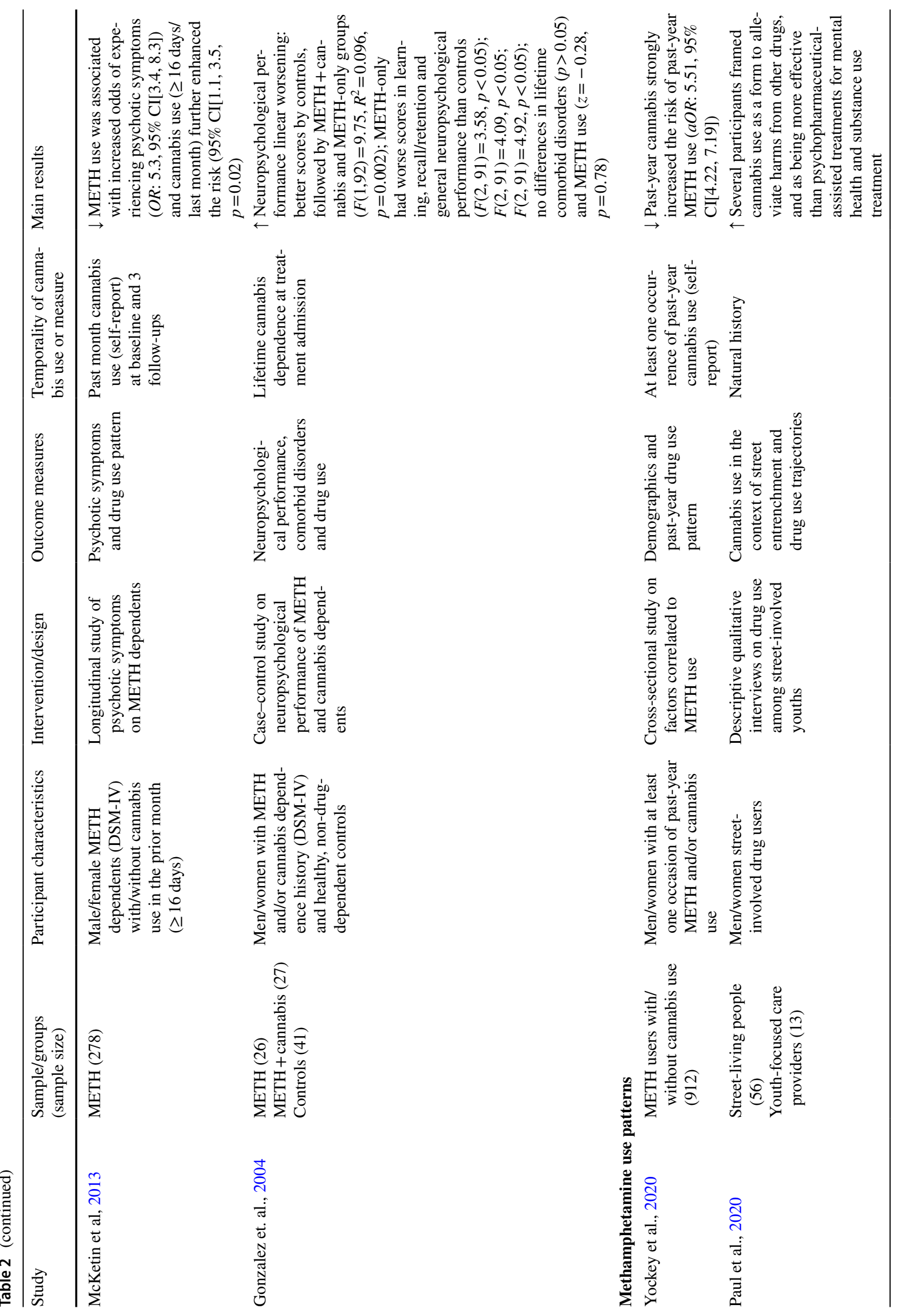




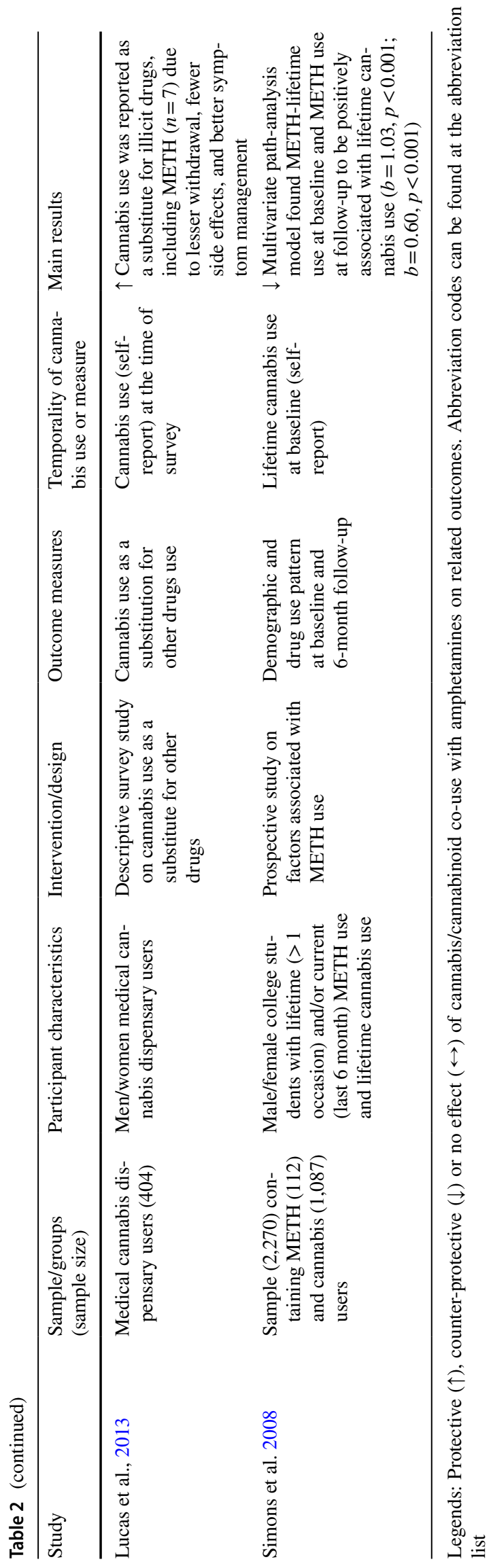


of amphetamine-induced place-preference $(F(3,32)=4.7$, $p<0.01$, post hoc $p<0.05$ ) (Parker et al. 2004). CBD (10, 20,40 and $80 \mathrm{mg} / \mathrm{kg}$, i.p.) administrated $1 \mathrm{~h}$ before methamphetamine ( $2 \mathrm{mg} / \mathrm{kg}$, i.p.) administration ( $n=3-10 /$ group) reduced methamphetamine-induced place preference in a dose-dependent manner $(p<0.05)$ and decreased several methamphetamine-induced signalling pathways (e.g. Sigma1 receptor, p-AKT, p-GSK-3 $\beta$, p-CREB) levels in the prefrontal cortex, nucleus accumbens, hippocampus, and ventral tegmental area (all $p<0.05$ ) (Yang et al. 2020). Single intracerebral ventricular CBD $(10 \mu \mathrm{g} / 5 \mu \mathrm{l})$ administration $60 \mathrm{~min}$ before methamphetamine $(0.25$ and $0.5 \mathrm{mg} / \mathrm{kg}$, s.c. $)$ administration in animals with/without sleep deprivation stress and methamphetamine-induced conditioned place preference ( $n=4-6 /$ group) impaired methamphetamine-reinstatement response in both sleep and non-sleep deprived animals $(F(3$, $22)=11.13, p<0.001 ; F(2,15)=18.29, p<0.001$, both post hoc $p<0.05$ ) (Karimi-Haghighi and Haghparast 2018). In a sequencing study with the same experimental conditions ( $n=4-5$ /group), IL-1 $\beta$, IL-6 and IL-10 mRNA expression in the prefrontal cortex, and TNF- $\alpha$, IL- $1 \beta$ and IL- 6 in the hippocampus were reduced in methamphetamine-induced reinstatement animals $(p<0.05)$. TNF- $\alpha$, IL-1 $\beta$, IL- 6 and IL-10 mRNA expression levels were augmented in the hippocampus, but IL-10 was reduced in the prefrontal cortex of sleep-deprivation-induced reinstatement animals $(p<0.05)$ (Karimi-Haghighi et al. 2020).

Two vehicle-controlled studies in rats assessed the effects of repeated THC administration on amphetamine-induced sensitization (i.e. a drug-dependent increase of locomotor activity). Repeated THC $(0.75,1.5$ and $3.0 \mathrm{mg} / \mathrm{kg}$, i.p. $)$ administration for 5 days ( $n=6-8 /$ group) had no effect on amphetamine-induced sensitization $(0.5$ and $2.0 \mathrm{mg} / \mathrm{kg}$, i.p. $)$ in adolescent or adult rats $(F(3,97)=0.38, p<0.001 ; F(4$, $95)=23.2, p<0.001$, post hoc $p>0.05)$ (Ellgren et al. 2004); however, $27 \mathrm{THC}(0.6,3$ and $15 \mathrm{mg} / \mathrm{kg}$, i.p.) administrations in a 3 -week period ( $n=9-12 /$ group), 3 and 55 days before amphetamine $(1 \mathrm{mg} / \mathrm{kg}$, i.p.) administration, increased amphetamine sensitization in previously high-locomotionresponsive animals shortly after treatment $(H(3)=7.27$, $p<0.05$, post hoc $p<0.05$ ), but not after longer time $(p>0.05)$ (Lamarque et al. 2001).

Overall, studies with non-contingent models of amphetamine/methamphetamine exposure showed a protective potential of CBD by reducing amphetamine reward and risk of relapse and facilitating related memory extinction. CBD was also shown to reduce neuroinflammatory factors in the brain, though it also enhanced the same factors in one specific (sleep-deprivation stress) condition. While THC was found to potentiate the extinction of amphetamine-related memory, it also showed no or counter-protective effects, specifically in vulnerable drug animals, as measured by methamphetamine sensitization.

\section{Contingent models of addiction $(n=3)$}

Three vehicle-controlled studies assessed the effects of single or repeated CBD or THC administration in rats trained to self-administer amphetamine or methamphetamine on cue- or amphetamine/methamphetamine-seeking (response to acquire drug), relapse (drug-seeking after drug selfadministration extinction) or reinstatement. Single CBD (20, 40 and $80 \mathrm{mg} / \mathrm{kg}$, i.p.) administration in animals trained to self-administer methamphetamine $(0.05 \mathrm{ml} /$ infusion, i.v. $)$ 30 min before methamphetamine-seeking and relapse trials ( $n=10-12 /$ experiment) attenuated, at $80 \mathrm{mg} / \mathrm{kg}$, methamphetamine-seeking and relapse responses $(F(1,9)=13.84$, $p=0.005 ; F(1.792,19.707)=45.96, p=0.021$ both post hoc $p<0.05)$, and at all doses reduced methamphetamineinduced hyperactivity $(F(3,33)=11.01, p<0.001$, all post hoc $p<00.05$ ) (Hay et al. 2018). Acute delta-8-THC $(0.32$, 1.0 and $3.2 \mathrm{mg} / \mathrm{kg}$, i.p.) administration before methamphetamine self-administration extinction sessions $(n=4-8 /$ group) attenuated, at $0.32 \mathrm{mg} / \mathrm{kg}$, methamphetamine-seeking $(F(3,23)=13.10, p<0.01$, post hoc $p<0.001)$, at $1 \mathrm{mg} / \mathrm{kg}$ enhanced methamphetamine cue-seeking $(F(1,10)=12.20$, $p<0.01$, post hoc $p<0.001)$ and at $3.2 \mathrm{mg} / \mathrm{kg}$ decreased methamphetamine- and cue-reinstatement $(F(2,19)=14.6$, $p<0.0001 ; F(1,10)=11.4, p<0.01$, both post hoc $p<0.01)$, while repeated delta- 8 -THC ( 5 days, $3.2 \mathrm{mg} / \mathrm{kg}$, i.p.) administration decreased methamphetamine-reinstatement $(F(2$, $20)=22.08, p<0.0001$, post hoc $p<0.001$ ) (Anggadiredja et al. 2004). However, five administrations of THC (0.4, $0.75,1.5,3.0$ and $6.0 \mathrm{mg} / \mathrm{kg}$ i.p.) in a 15 -day period before amphetamine administration $(0.75 \mathrm{mg} / \mathrm{kg}$, i.p. $)$ in animals with amphetamine self-administration history $(n=6-12 /$ group) had no effect on dopamine levels and amphetamine self-administration (data not shown), but increased amphetamine-sensitization $(F(5,30)=2.80, p<0.05 ; F(5,30)=2.70$, $p<0.05$, both post hoc $p<0.05$ ) (Cortright et al. 2011).

Overall, contingent models of amphetamine/methamphetamine addiction studies generally showed a relapse-preventive potential of $\mathrm{CBD}$ and $\mathrm{THC}$ by reducing the motivation to seek and consume methamphetamine, while one study showed THC to increase amphetamine-induced hyperlocomotion but without affecting its self-administration.

\section{Amphetamine-induced mental health model or neurotoxicity $(n=6)$}

Four vehicle-controlled studies assessed the effects of single or repeated CBD administration, either by intraperitoneal or intra-nucleus accumbens injections, before (D-) amphetamine administration in a model of human psychoses/mental health (e.g. schizophrenia, bipolar disorder) on behavioural and neurobiological outcomes. Single CBD $(15,30$ and $60 \mathrm{mg} / \mathrm{kg}$, i.p.) administration in mice $(n=7 /$ 
group) 20 min before $\mathrm{D}$-amphetamine administration $(5 \mathrm{mg} / \mathrm{kg}$, i.p.), at 30 and $60 \mathrm{mg} / \mathrm{kg}$, reduced D-amphetamine-induced hyperlocomotion and total distance travelled at selected time-points $(F(45,132)=1.49, p=0.044$, post hoc $p<0.05$ ) (Moreira and Guimarães 2005). Single CBD (60 nmol/0.2 $\mu \mathrm{l}$, intra-accumbens) administration in mice ( $n=8-10$ /group) immediately before amphetamine $(10,30$ and $60 \mathrm{mg} / \mathrm{kg}$, i.p.) administration and 10-30 min before pre-pulse inhibition test (i.e. reflex response inhibition by a weak sensory event) attenuated amphetamine-induced pre-pulse impairment $(F(1,25)=6.38, p=0.018$, post hoc $p<0.05)$, but this effect was only marginally significant at 30 and $60 \mathrm{mg} / \mathrm{kg}$ doses $(F(3,67)=4.09, p=0.07$, post hoc $p<0.05$ ) (Pedrazzi et al. 2015). Repeated CBD (100 ng/0.5 ul, intra-accumbens) for five or 16 days and (in another group) immediately before a $\mathrm{D}$-amphetamine-induced (100 ng/0.5 ul, intra-accumbens) model of schizophrenia in rats ( $n=8-10 /$ group) decreased D-amphetamine-induced hyperlocomotion, dopaminergic neuronal sensitization $(F(3,36)=18.711, p<0.001 ; F(5,113)=4.17, p<0.01$, both post hoc $p<0.05)$ and modified ventral tegmental area molecular pathways (e.g. mTOR and p70S6K increase $t(6)=-3.60, p<0.05 ; \mathrm{t}(6)=-3.70, p<0.05)($ Renard et al. 2016). However, twice-daily CBD (15, 30 and $60 \mathrm{mg} /$ $\mathrm{kg}$, i.p.) administration for 6 or 14 days ( $n=5 /$ group), partially concomitant to repeated D-amphetamine $(2 \mathrm{mg} / \mathrm{kg}$, i.p.) administration, did not reverse or prevent a bipolar manic model (i.e. D-amphetamine-induced hyperlocomotion) (data not shown), but at $15 \mathrm{mg} / \mathrm{kg}$ protected from the D-amphetamine-induced brain damage and at $30 \mathrm{mg} /$ $\mathrm{kg}$ increased BDNF levels in the hippocampus $(p<0.05)$ (Valvassori et al. 2011).

Two studies investigated the effect of THC or CBD administration on methamphetamine-induced neurotoxicity on behavioural or biological outcomes of rats. Single THC ( 1 and $3 \mathrm{mg} / \mathrm{kg}$, i.p.) administration before or after methamphetamine-induced $(10 \mathrm{mg} / \mathrm{kg}$, s.c.) neurotoxicity (total $n=109$ ) decreased caudate-putamen GFAP-IR and nNOS-positive neurons in selected doses $(F(2,32)=8.12$, $p=0.001 ; F(2,37)=20.53, p<0.001$, both post hoc $p<0.01)$ and in all doses decreased cingulate cortex GFAPIR $(F(2,32)=25.49, p<0.001$, post hoc $p<0.001)$ but did not affect METH-increased body temperature (Castelli et al. 2014). Repeated CBD administration (32 and $160 \mathrm{nmol}$ i.c.v./day) during a 10-day methamphetamine-abstinence period did not affect methamphetamine-induced hyperlocomotion $(F(2,21)=0.08 ; p>0.05)$, but both doses reversed methamphetamine-induced spatial memory impairment $(F(4,37)=7.12 ; p<0.001$, post hoc $p<0.05)$, short-term memory impairment $(F(4,40)=3.472 ; p<0.005$; post hoc $p<0.05)$ and at $160 \mathrm{nmol}$, long-term memory impairment $(F(2,22)=50.36 ; p<0.025$, post hoc $p<0.05$ ) (Razavi et al. 2020).
Overall, for amphetamine-induced mental health, there was a CBD-related protective effect for amphetamine/ methamphetamine-induced animal models of psychosis but not mania, suggesting antipsychotic-like action. Also, CBD and THC protected against amphetamine/methamphetamineinduced brain damage.

\section{Studies in humans}

\section{Brain structure/metabolism $(\mathbf{n}=3)$}

Two case-control studies compared adolescents with methamphetamine dependence, methamphetamine and cannabis dependence and healthy controls on their brain structure or metabolism. Using proton magnetic resonance spectroscopy (MRS) to investigate neurochemical toxicity in the cingulate brain area in South African adolescents ( $n=8-10 /$ group), Sung et al. (2013) found no betweengroup differences in $\mathrm{mI} / \mathrm{PCr}+\mathrm{Cr}, \mathrm{GPC}+\mathrm{PC} / \mathrm{PCr}+\mathrm{Cr}$ and $\mathrm{Glu}+\mathrm{Gln} / \mathrm{PCr}+\mathrm{Cr}$ metabolite $(p>0.05)$, but methamphetamine and cannabis dependents (criteria not specified) had lower tNAA/ $\mathrm{PCr}+\mathrm{Cr}$ ratio than methamphetamineonly dependent subjects and healthy, non-drug-dependent controls $(F(2,22)=4.23, p=0.03$, post hoc $p<0.05)$. Also, tNAA/PCr $+\mathrm{Cr}$ ratio correlated with several drug use patterns, e.g. a negative correlation with methamphetamine and cannabis life-time-doses $(F(1,6)=11.13$, $p=0.02 ; F(1,6)=11.44, p=0.02)$. Churchwell et al. (2012) used structural magnetic resonance images (MRI) and found methamphetamine- and cannabis-dependent (DSM-IV) US-based adolescents ( $n=9-10 /$ group) to have greater left putamen volume and higher novelty-seeking scores than healthy, non-drug-dependent controls $(F(2$, $24)=4.94, p<0.02 ; F(2,24)=3.56, p<0.04$, both post hoc $p<0.05$ ); also, lifetime methamphetamine doses positively correlated to left putamen volume in methamphetamine and methamphetamine + cannabis dependents $(r(9)=0.56, p=0.05 ; r(8)=0.65, p=0.04)$, and with novelty-seeking in methamphetamine-only dependents $(r(9)=0.64, p<0.03)$.

Another study, using positron emission tomographic (PET) in US-based methamphetamine users with/without cannabis co-use ( $>4$ joints/month, $n=7 /$ group) during an auditory performance task (i.e. discrimination of highpitched tone among lower-pitched tone distracters) found methamphetamine + cannabis users to have lower cerebral glucose metabolism (rCMRglc) in several brain regions, e.g. right orbitofrontal cortex, temporal gyrus, hippocampus (all $p<0.05$ ) but no difference in auditory performance accuracy (mean $\pm S E M[\log 1+\%$ errors]): $0.69 \pm 0.16 ; 0.80 \pm 0.10$ ) or reaction time $(0.65 \pm 0.06 ; 0.75 \pm 0.07)$ was found (Voytek et al. 2005). 
Overall, brain structure and metabolism studies showed that cannabinoids co-use with methamphetamines is associated with neurotoxicity and abnormal brain function.

\section{Neuropsychological function or psychopathology symptoms $(n=3)$}

Two case-control studies assessed neuropsychological performance in adolescents or adults with methamphetamine dependence, methamphetamine + cannabis dependence and healthy controls. One study among South African adolescents with methamphetamine + cannabis dependence (DSMIV) $(n=10)$ found their performance to be impaired in several neuropsychological tasks (e.g. verbal memory, planning, all $p<0.05)$ compared to healthy, non-drug-dependent controls $(n=20)$, and worse verbal memory $(p<0.001)$ compared to methamphetamine-only dependents $(n=10)$ (Cuzen et al. 2015). Conversely, Gonzalez et al. (2004) reported a linear worsening of neuropsychological performance in a US-based adult sample when considering lifetime cannabis/methamphetamine dependence (DSM-IV), with better scores in the control (i.e. healthy, non-drug dependents) group ( $n=41)$, followed by methamphetamine + cannabis $(n=27)$ and methamphetamine-only dependents $(n=26)$ groups $\left(F(1,92)=9.75, R^{2}=0.096, p=0.002\right)$. Moreover, methamphetamine-only dependents had worse learning, recall/retention and general neuropsychological performance scores than controls $(F(2,91)=3.58, p<0.05)$; $F(2,91)=4.09, p<0.05 ; F(2,91)=4.92, p<0.05$, all post hoc $p<0.05)$. This same study also did not find betweengroup differences in lifetime psychiatric comorbid disorders $(p>0.05)$ and methamphetamine use among groups $(z=-0.28, p=0.78)$.

In regard to psychopathology, an Australian-based longitudinal prospective cohort with methamphetamine dependents (DSM-IV, $n=278$ ) found prior-month methamphetamine use to be associated with increased odds of experiencing psychotic symptoms (OR: 5.3, 95\% CI [3.4, 8.3]) and prior-month cannabis use ( $\geq 16$ days) to further increase the odds of experiencing psychotic symptoms $(95 \%$ CI $[1.1,3.5], p=0.02)$, even when controlling for alcohol use (McKetin et al. 2013).

Overall, two studies suggested that cannabis co-use was associated with increased methamphetamine-related harm by increasing neurocognitive impairment and psychotic symptoms, while one found no exacerbation of cannabis exposure on methamphetamine-related neurotoxicity measures.

\section{Methamphetamine use patterns $(n=4)$}

Two US-based studies assessed different factors associated with methamphetamine use, including cannabis use. A crosssectional study with 18-34-year-old methamphetamine-users (at least 1 prior-year use instance) using data from the population-representative National Survey of Drug Use and Health (NSDUH, 2015/18) found that self-reported past-year cannabis use strongly increased the risk of past-year methamphetamine use $(n=912)(a O R: 5.51,95 \%$ CI [4.22, 7.19]) (Yockey et al. 2020). A prospective study among a convenience sample of rural area college students (18-25 years old), based on a self-report electronic questionnaire containing methamphetamine $(n=112)$ and cannabis $(n=1,087)$ users, found methamphetamine-lifetime use at baseline and methamphetamine-use at 6-month follow-up (controlled by lifetime-methamphetamine use) to be positively associated with lifetime cannabis use $(b=1.03, p<0.001 ; b=0.60$, $p<0.001)$, although $89 \%$ of cannabis users reported having never used methamphetamine at 6-month follow-up (Simons et al. 2008).

Two Canada-based descriptive studies explored the influence of cannabis use on the use of other drugs (including methamphetamine) from the participants' perspectives. A study with anonymous self-reported survey-data from a sample of medical cannabis dispensary users $(n=404)$ reported cannabis use as a substitute for illicit drugs (36.1\%), including methamphetamine $(n=7)$, due to perceived lesser withdrawal, fewer side effects and better symptom management characteristics ascribed to cannabis use (Lucas et al. 2013). In-depth qualitative interviews with street-involved young people (16-26 years old, $n=56)$ and youth-focused care providers $(n=13)$ reported that most drug users engaged in daily cannabis use at the same time as they used other substances (including methamphetamine), and several participants described cannabis use as a form to alleviate harms from other drugs' use. Respondents also perceived cannabis use as being more effective than psychopharmaceutical-assisted treatments for mental health and substance use treatment, and few participants reported harms related to the intensive-cannabis use (Paul et al. 2020).

Overall, two studies on methamphetamine use patterns showed cannabis use to be associated with increased methamphetamine use; conversely, two self-reports suggested cannabis use to alleviate harms from, or to substitute for, methamphetamine use.

\section{Discussion}

Animal studies retrieved in this review showed mostly protective effects of both CBD and THC upon amphetamine exposure in models used to investigate several phases of amphetamine addiction (e.g. drug-seeking, relapse, extinction) (Kuhn et al. 2019; Spanagel 2017), and neurobiological markers (e.g. neurotoxicity, brain damage). While almost all CBD-based studies disclosed protective results, including for alleviating amphetamine-induced psychosis, some 
studies with THC-agents reported no effect and one showed a counter-protective effect, suggesting a facilitated progression of THC towards amphetamine use in vulnerable individuals (i.e. prior high-locomotion responsive animals).

The endocannabinoid system has been a topic of growing interest as a possible target for treating craving and addiction given its relationship to reward pathways, and substances acting on this system have been suggested as possible candidates for the pharmacotherapeutic treatment of substance use disorders (Batalla et al. 2019; Chye et al. 2019; Manzanares et al. 2018; Parsons and Hurd 2015; Prud'homme et al. 2015; Spanagel 2020). Although the full mechanisms of action of CBD are yet to be determined, CBD has been reported to act as a negative allosteric modulator of the $\mathrm{CB}_{1}$ receptor and is unlikely to produce a rewarding effect (e.g. voluntary self-administration) (Ibeas Bih et al. 2015; Laprairie et al. 2015; Spanagel 2020). CBD also exerts its actions through other circuitry relevant to addictive disorder (e.g. 5HT1a, $\alpha 7$-nicotinic receptors), and some of its pharmacological effects such as reversing amphetamine-induced neuroinflammation and cognitive deficits, as well as alleviating mental disorder comorbidities (e.g. anxiety, depression) can be implied as a therapeutic benefit for amphetamine addiction (Calpe-López et al. 2019; Manzanares et al. 2018). In contrast, THC features substantial differences in its pharmacological actions that may account for the more heterogeneous results. By acting as an agonist of the $\mathrm{CB}_{1}$ receptor, THC produces a dose-sensitive rewarding effect, with increasing doses shifting to negative, instead of positive, reinforcement (Spanagel 2020). Moreover, the differences in results observed in THC studies, ranging from protective to counterprotective effects, indicate a possible benefit from THC to amphetamine addiction that may depend on experimental factors (e.g. dose, length and timing of administration).

Overall, pre-clinical studies identified in this review aggregate evidence that phyto-cannabinoids, especially $\mathrm{CBD}$, may have protective potential both for amphetamine addiction in several phases (e.g. relapse, abstinence) and for other amphetamine-related consequences (e.g. neurotoxicity). Also, CBD showed some protective effects for amphetamine-induced models of psychosis. Amphetamine-induced sensitization is a useful animal model for assessing human mental health conditions (e.g. schizophrenia, mania) that relies on the behavioural and neurochemical, including toxic, effects of amphetamine (Featherstone et al. 2007; Young et al. 2011). Moreover, investigating CBD's potential on the amphetamine-induced model of mental health can provide insights into behavioural and neuroprotective factors that may be used translationally not only for specific mental illness populations, but also to amphetamine users. For instance, some of the known psychiatric (e.g. acute mania or psychotic) symptoms of amphetamine exposure observed in different populations (Anand et al. 2000; Curran et al. 2004;
McKetin et al. 2013; Strakowski and Sax 1998) could be reduced by CBD-related actions.

In contrast, studies in human mostly showed counter-protective effects or no effect on the co-use of cannabis with amphetamine for several outcomes, including brain (e.g. MRS, MRI), mental health, cognition (e.g. neuropsychological performance, psychotic symptoms) and amphetamine use. Several factors may account for the observed discrepancies with the human-based results and the growing body of literature suggesting a therapeutic potential of cannabinoids for addictive, including psychostimulant- and amphetaminerelated behaviours (Abrams 2018; Prud'homme et al. 2015). First, these studies are highly heterogeneous, with fundamental differences in design (e.g. case-control, longitudinal, prospective), cannabis use pattern (e.g. use or dependence), outcomes measured and population studied (e.g. college students, drug dependents). One major difference between the pre-clinical and human studies that may account to the discrepant results is the cannabinoid/cannabis exposure pattern. While all human studies assessed cannabis and amphetamines co-used within a naturalistic form of use and/ or dependence, with no studies assessing the direct administration (e.g. experimental setting) of cannabis or cannabis products (e.g. CBD, THC, Sativex®) on amphetamine users, pre-clinical studies did not evaluate cannabinoids within an abuse model (e.g. THC self-administration learning, conditioned place preference).

Given the non-clinical nature, the human studies included did not control other relevant factors on addiction, such as drug (cannabinoid)-related conditioned response (e.g. eliciting drug desire, triggering relapse) and social interactions (Bardo et al. 2013; Kenny et al. 2003; O'Brien et al. 1998; Pelloux et al. 2019). In addition to the common pathway (i.e. inhalation) that cannabis and amphetamine use may share, the ongoing, naturalistic use of cannabis by participants, often taken as co-dependence, may entail a poly-substance use scenario, which is commonly associated with more cooccurring and/or severe problems (e.g. psychological distress, anxiety, depression) among users (Connor et al. 2013, 2014). Also, it could be possible that amphetamine users with co-morbid conditions use cannabis in an attempt to self-regulate or self-treat comorbid mental health or cognitive problems experienced. Some qualitative reports, mostly focusing on crack cocaine but also methamphetamine use, highlight intentional cannabis use patterns towards alleviation of psychostimulant-related problems (Andrade et al. 2011; Gonçalves and Nappo 2015; Paul et al. 2020).

On this basis, the absence of more controlled studies (e.g. clinical trials) for psychostimulants, and for amphetamines specifically, still represents a major gap in the field; conducting such studies would allow for a better translation of the pre-clinical findings into human/clinical setting. Despite these translational limitations, some of the human studies 
in this review suggest that cannabis use, especially when involving subjects with substance use disorder/dependence, may entail increased risks for adverse outcomes or co-morbidities among users, which highlights the importance of considering potential cannabis use-related risks as much as its therapeutic potential among amphetamine users.

Two descriptive studies in human samples reported cannabis use reducing amphetamine use-related harms and detrimental effects, including one qualitative in-depth selfreport study. Similar results have been reported more frequently for the co-use of cannabis with crack cocaine, and some observers have already proposed for cannabis application use a pragmatic, substitutive or therapeutic option for other harmful drug use to be further investigated (Andrade et al. 2011; Gonçalves and Nappo 2015; Lau et al. 2015; Socías et al. 2017). Different dynamics in the context of drug use, motivational aspects or subpopulation specificities could be involved in these contrasting, protective results. However, while descriptive designs with qualitative approaches are relevant to investigate specific populations (Patton 2015), the identified studies are limited in nature since they rely on participants' (or others') subjective perception/beliefs and lack control measures for generalization (e.g. control group, standardized measures, biased sample), and, as such, conclusions are limited. At best, these results, together with the mostly enhanced harm outcomes in human study populations described, suggest that any possible benefits from cannabis use regarding amphetamines addiction is likely strongly dependent on patterns of cannabis use (e.g. timing, motivation, dependence).

Although the limitations of the studies in humans showing some protective effects related to cannabinoids use (i.e. less frequently and/or less controlled than studies finding counter-protective effects), they reinforce, together with the pre-clinical studies' results, the necessity to conduct controlled studies on cannabinoids and their potential to alleviate amphetamine addiction or amphetamine-related deficits. Overall, in addition (or due) to the non-specific cannabinoid's, especially CBD, mechanisms, the therapeutic potential for substance use disorder may crucially vary according to the substance. For example, when considering other types of psychostimulants, two randomized controlled trials with repeated CBD administration on cocaine or crack cocaine users found no differences in cue-induced craving or relapse risk (Meneses-Gaya et al. 2020; Mongeau-Pérusse et al. 2021); conversely, controlled trials found a protective action of CBD for other drug classes (e.g. cannabinoids, opioids), either by reducing cue-induced craving or drug consumption (Freeman et al. 2020; Hurd et al. 2019; Morgan et al. 2013). For the specific case of amphetamines, there are different pathways in which CBD may have therapeutic effects for addiction-related outcomes. CBD agonist actions on serotoninergic and dopaminergic receptors could play a relevant role, given that the agonist action on 5-HT1a receptors can inhibit behaviours related to addiction, and partial dopaminergic agonists have been shown to attenuate stimulants self-administration in pre-clinical models (CalpeLópez et al. 2019; Müller and Homberg 2015). Nevertheless, while much emphasis has been given on whether cannabinoids may help with problematic substance use-related craving and relapse, a main role for cannabinoid products may also be able to decrease deleterious biological impact (e.g. neuronal toxicity, psychiatric symptoms) of amphetamines and other drugs, as has been demonstrated by several of the pre-clinical studies included in this review (Castelli et al. 2014; Karimi-Haghighi et al. 2020; Prud'homme et al. 2015; Razavi et al. 2020; Valvassori et al. 2011).

The present review's limited search and selection approach, including English-language studies only, number of databases, exclusive reliance on peer-reviewed (i.e. no grey literature) studies, may imply limitations of the present work. Furthermore, no meta-analyses of the study data were done given the heterogeneous approach and designs. In conclusion, data from pre-clinical studies suggest potentially protective effect of THC and CBD regarding amphetamine (or methamphetamine)-related addiction behaviour and impairments, while human studies, despite some preliminary protective results limited to specific populations, suggest greater morbidity between the co-use of cannabis and amphetamines in a range of (e.g. brain, cognitive, health) outcomes but mostly assessing natural cannabis use or abuse. Given recent evidence of increasing psychostimulant use and harms (e.g. in North America and elsewhere (Farrell et al. 2019; Fischer et al. 2021; Strickland et al. 2019)) and substantive pre-clinical evidence of cannabinoids therapeutic potential for addiction (Chye et al. 2019; Parsons and Hurd 2015), the dearth of systematic, rigorous (e.g. controlled clinical) studies assessing the potentially beneficial effects of cannabinoids on amphetamine-related health or behavioural outcomes should urgently be addressed.

Abbreviations AMPH: Amphetamine; aOR: Adjusted odds ratio; BDNF: Brain-derived neurotrophic factor; CBD: Cannabidiol; CB1: Cannabinoid receptor 1; CB2: Cannabinoid receptor 2; CI: Confidence interval; delta-8-THC: Delta-8-tetrahydrocannabinol; ECS: Endocannabinoid system; GFAP: Glial fibrillary acidic protein; $\mathrm{Glu}+\mathrm{Gln} / \mathrm{PCr}+\mathrm{Cr}$ : Glutamate plus glutamine/phosphocreatine plus creatine ratio; $\mathrm{GPC}+\mathrm{PC} / \mathrm{PCr}+\mathrm{Cr}$ : Glycerophosphocholine plus phosphocholine/phosphocreatine plus creatine ratio; i.c.: Intracerebral; i.c.v.: Intracerebral ventricular; IL-1 $\beta$ : Interleukin $1 \beta$; IL-6: Interleukin 6; IL-10: Interleukin 10; i.p.: Intraperitoneal; METH: Methamphetamine; $\mathrm{mI} / \mathrm{PCr}+\mathrm{Cr}$ : Myo-inositol/phosphocreatine plus creatine ratio; MRS: Proton magnetic resonance spectroscopy; mRNA: Messenger RNA; mTOR: Mammalian target of rapamycin; NSDUH: National Survey of Drug Use and Health; OR: Odds ratio; p-AKT: Phosphorylated protein kinase B; p-CREB: Phosphorylated cAMP-response element binding protein; PET: Positron emission tomography; p-GSK-3 $\beta$ : Phosphorylated glycogen synthase kinase $3 \beta$; PPI: Prepulse inhibition; PRESS: Peer Review Electronic Search Strategies; p70S6K: P70S6 
kinase; rCMRglc: Lower cerebral glucose metabolism; s.c.: Subcutaneous; SEM: Standard error of the mean; THC: Tetrahydrocannabinol; tNAA/PCr + Cr: N-acetylaspartate plus $\mathrm{N}$-acetylaspartyl glutamate/ phosphocreatine plus creatine ratio; TNF- $\alpha$ : Tumor necrosis factor $\alpha$; US: United States; 5-HT: 5-Hydroxytryptamine (serotonin

Supplementary Information The online version contains supplementary material available at https://doi.org/10.1007/s00213-021-05960-2.

Author contribution BF developed the concept for the study. DDB developed the review strategy and led the data collection and writing for the paper. DDB and LOM extracted, collated and analysed the data. All co-authors contributed to data/results interpretation and provided substantial intellectual content towards iterative drafts and revisions of the paper. All authors approved the final version of the paper submitted.

Funding Prof. Fischer acknowledges support from the endowed Hugh Green Foundation Chair in Addiction Research, Faculty of Medical and Health Sciences, University of Auckland; he furthermore reports research grants and contract funding from public only (e.g. public funding, government) agencies. Didier Jutras-Aswad holds a scholar award from the Fonds de recherche du Québec en Santé and has received investigational product from Insys Therapeutics for a clinical trial funded by the Canadian Institutes of Health Research; he furthermore reports research grants and contract funding from public (e.g. public funding, government) agencies.

\section{Declarations}

Ethics aproval This article is based on previously conducted studies and published data and does not involve any studies with human participants or animals performed by any of the authors.

Conflict of interest The authors declare no competing interest.

Open Access This article is licensed under a Creative Commons Attribution 4.0 International License, which permits use, sharing, adaptation, distribution and reproduction in any medium or format, as long as you give appropriate credit to the original author(s) and the source, provide a link to the Creative Commons licence, and indicate if changes were made. The images or other third party material in this article are included in the article's Creative Commons licence, unless indicated otherwise in a credit line to the material. If material is not included in the article's Creative Commons licence and your intended use is not permitted by statutory regulation or exceeds the permitted use, you will need to obtain permission directly from the copyright holder. To view a copy of this licence, visit http://creativecommons.org/licenses/by/4.0/.

\section{References}

Abrams DI (2018) The therapeutic effects of cannabis and cannabinoids: an update from the National Academies of Sciences, Engineering and Medicine report. Eur J Intern Med 49:7-11. https:// doi.org/10.1016/j.ejim.2018.01.003

Anand A, Verhoeff P, Seneca N, Zoghbi SS, Seibyl JP, Charney DS, Innis RB (2000) Brain SPECT imaging of amphetamine-induced dopamine release in euthymic bipolar disorder patients. Am J Psychiatry 157:1108-1114. https://doi.org/10.1176/appi.ajp. 157.7.1108

Andrade T, Santiago L, Amari E, Fischer B (2011) 'What a pity!' exploring the use of 'pitilho' as harm reduction among crack users in Salvador Brazil. Drugs Ed Prev Policy 18:382-386. https://doi.org/10.3109/09687637.2010.506898

Anggadiredja K, Nakamichi M, Hiranita T, Tanaka H, Shoyama Y, Watanabe S, Yamamoto T (2004) Endocannabinoid system modulates relapse to methamphetamine seeking: possible mediation by the arachidonic acid cascade. Neuropsychopharmacology 29:1470-1478. https://doi.org/10.1038/sj.npp.1300454

Arksey H, O’Malley L (2005) Scoping studies: towards a methodological framework. Int J Soc Res Methodol 8:19-32. https://doi.org/ 10.1080/1364557032000119616

Bardo MT, Neisewander JL, Kelly TH (2013) Individual differences and social influences on the neurobehavioral pharmacology of abused drugs. Pharmacol Rev 65:255-290. https://doi.org/10. 1124/pr.111.005124

Batalla A, Janssen H, Gangadin SS, Bossong MG (2019) The potential of cannabidiol as a treatment for psychosis and addiction: who benefits most? A systematic review. J Clin Med 8. https://doi.org/ $10.3390 / \mathrm{jcm} 8071058$

Brandt L, Chao T, Comer SD, Levin FR (2020) Pharmacotherapeutic strategies for treating cocaine use disorder - what do we have to offer? Addiction. https://doi.org/10.1111/add.15242

Cabral GA, Ferreira GA, Jamerson MJ (2015) Endocannabinoids and the immune system in health and disease. Handb Exp Pharmacol 231:185-211. https://doi.org/10.1007/978-3-319-20825-1_6

Calpe-López C, García-Pardo MP, Aguilar MA (2019) Cannabidiol treatment might promote resilience to cocaine and methamphetamine use disorders: a review of possible mechanisms. Molecules 24. https://doi.org/10.3390/molecules 24142583

Castelli MP et al (2014) $\Delta$ 9-tetrahydrocannabinol prevents methamphetamine-induced neurotoxicity. PloS one 9:e98079. https://doi. org/10.1371/journal.pone.0098079

Castells X, Cunill R, Pérez-Mañá C, Vidal X, Capellà D (2016) Psychostimulant drugs for cocaine dependence. Cochrane Database Syst Rev. https://doi.org/10.1002/14651858.CD007380.pub4

Churchwell JC, Carey PD, Ferrett HL, Stein DJ, Yurgelun-Todd DA (2012) Abnormal striatal circuitry and intensified novelty seeking among adolescents who abuse methamphetamine and cannabis. Dev Neurosci 34:310-317. https://doi.org/10.1159/00033 7724

Chye Y, Christensen E, Solowij N, Yücel M (2019) The endocannabinoid system and cannabidiol's promise for the treatment of substance use disorder. Frontiers in Psychiatry 10. https://doi.org/ 10.3389/fpsyt.2019.00063

Connor J, Gullo M, Chan G, Young R, Hall W, Feeney G (2013) Polysubstance use in cannabis users referred for treatment: drug use profiles, psychiatric comorbidity and cannabis-related beliefs. Frontiers in Psychiatry 4. https://doi.org/10.3389/fpsyt.2013. 00079

Connor JP, Gullo MJ, White A, Kelly AB (2014) Polysubstance use: diagnostic challenges, patterns of use and health. Curr Opin Psychiatry 27:269-275. https://doi.org/10.1097/yco.0000000000 000069

Cortright JJ, Lorrain DS, Beeler JA, Tang WJ, Vezina P (2011) Previous exposure to delta9-tetrahydrocannibinol enhances locomotor responding to but not self-administration of amphetamine. J Pharmacol Exp Ther 337:724-733. https://doi.org/10.1124/jpet. 111.180208

Crippa JA, Guimarães FS, Campos AC, Zuardi AW (2018) Translational investigation of the therapeutic potential of cannabidiol (CBD): toward a new age. Front Immunol 9:2009. https://doi. org/10.3389/fimmu.2018.02009

Cumming C, Kinner SA, McKetin R, Li I, Preen D (2020) Methamphetamine use, health and criminal justice system outcomes: a systematic review. Drug Alcohol Rev 39:505-518. https://doi. org/10.1111/dar.13062 
Cumming C, Troeung L, Young JT, Kelty E, Preen DB (2016) Barriers to accessing methamphetamine treatment: a systematic review and meta-analysis. Drug Alcohol Depend 168:263-273. https:// doi.org/10.1016/j.drugalcdep.2016.10.001

Curran C, Byrappa N, McBride A (2004) Stimulant psychosis: systematic review. Br J Psychiatry 185:196-204. https://doi.org/10. 1192/bjp.185.3.196

Cuzen NL, Koopowitz S-M, Ferrett HL, Stein DJ, Yurgelun-Todd D (2015) Methamphetamine and cannabis abuse in adolescence: a quasi-experimental study on specific and long-term neurocognitive effects. BMJ Open 5:e005833. https://doi.org/10.1136/bmjop en-2014-005833

Degenhardt L et al (2013) Global burden of disease attributable to illicit drug use and dependence: findings from the global burden of disease study 2010. Lancet (london, England) 382:1564-1574. https://doi.org/10.1016/s0140-6736(13)61530-5

Ellgren M, Hurd YL, Franck J (2004) Amphetamine effects on dopamine levels and behavior following cannabinoid exposure during adolescence. Eur J Pharmacol 497:205-213. https://doi.org/10. 1016/j.ejphar.2004.06.048

Farrell M et al (2019) Responding to global stimulant use: challenges and opportunities. Lancet (london, England) 394:1652-1667. https://doi.org/10.1016/S0140-6736(19)32230-5

Featherstone RE, Kapur S, Fletcher PJ (2007) The amphetamineinduced sensitized state as a model of schizophrenia. Prog Neuropsychopharmacol Biol Psychiatry 31:1556-1571. https://doi. org/10.1016/j.pnpbp.2007.08.025

Fischer B et al (2015a) Effectiveness of secondary prevention and treatment interventions for crack-cocaine abuse: a comprehensive narrative overview of English-language studies. Int J Drug Policy 26:352-363. https://doi.org/10.1016/j.drugpo.2015.01.002

Fischer B, Kuganesan S, Gallassi A, Malcher-Lopes R, van den Brink W, Wood E (2015b) Addressing the stimulant treatment gap: a call to investigate the therapeutic benefits potential of cannabinoids for crack-cocaine use. Int J Drug Policy 26:1177-1182. https://doi.org/10.1016/j.drugpo.2015.09.005

Fischer B, O'Keefe-Markman C, Lee A, Daldegan-Bueno D (2021) 'Resurgent', 'twin' or 'silent' epidemic? A select data overview and observations on increasing psychostimulant use and harms in North America. Subt Abuse Treat Prevent Policy 16(17). https:// doi.org/10.1186/s13011-021-00350-5

Freeman TP et al (2020) Cannabidiol for the treatment of cannabis use disorder: a phase $2 \mathrm{a}$, double-blind, placebo-controlled, randomised, adaptive Bayesian trial. Lancet Psychiat 7:865-874. https://doi.org/10.1016/S2215-0366(20)30290-X

GlobeNewswire (2020) GW Pharmaceuticals plc and Its U.S. Subsidiary Greenwich Biosciences, Inc. Announce That EPIDIOLEX® (cannabidiol) oral solution has been descheduled and is no longer a controlled substance. GW Pharmaceuticals plc. https://www. globenewswire.com/news-release/2020/04/06/2012160/0/en/ GW-Pharmaceuticals-plc-and-Its-U-S-Subsidiary-GreenwichBiosciences-Inc-Announce-That-EPIDIOLEX-cannabidiol-OralSolution-Has-Been-Descheduled-And-Is-No-Longer-A-Contr olled-Substan.html. Accessed June 172021

GlobeNewswire (2021) GW Pharmaceuticals receives European commission approval for EPIDYOLEX® (cannabidiol) for the treatment of seizures associated with tuberous sclerosis complex. GW Pharmaceuticals plc. https://www.globenewswire.com/en/ news-release/2021/04/20/2213053/26153/en/GW-Pharmaceut icals-receives-European-Commission-approval-for-EPIDY OLEX-cannabidiol-for-the-treatment-of-seizures-associatedwith-tuberous-sclerosis-complex.html. Accessed June 172021

Gonçalves JR, Nappo SA (2015) Factors that lead to the use of crack cocaine in combination with marijuana in Brazil: a qualitative study. BMC Public Health 15:706. https://doi.org/10.1186/ s12889-015-2063-0
Gonzalez R et al (2004) Neurocognitive performance of methamphetamine users discordant for history of marijuana exposure. Drug Alcohol Depend 76:181-190. https://doi.org/10.1016/j.druga lcdep.2004.04.014

Hay GL et al (2018) Cannabidiol treatment reduces the motivation to self-administer methamphetamine and methamphetamine-primed relapse in rats. J Psychopharmacol 32:1369-1378. https://doi.org/ $10.1177 / 0269881118799954$

Hurd YL et al (2019) Cannabidiol for the reduction of cue-induced craving and anxiety in drug-abstinent individuals with heroin use disorder: a double-blind randomized placebo-controlled trial. Am J Psychiatry 176:911-922. https://doi.org/10.1176/appi.ajp. 2019.18101191

Ibeas Bih C, Chen T, Nunn AV, Bazelot M, Dallas M, Whalley BJ (2015) Molecular targets of cannabidiol in neurological disorders. Neurotherapeutics 12:699-730. https://doi.org/10.1007/ s13311-015-0377-3

Jutras-Aswad D, Le Foll B, Bruneau J, Wild TC, Wood E, Fischer B (2019) Thinking beyond legalization: the case for expanding evidence-based options for cannabis use disorder treatment in Canada. Can J Psychiat 64:82-87. https://doi.org/10.1177/07067 43718790955

Karimi-Haghighi S, Dargahi L, Haghparast A (2020) Cannabidiol modulates the expression of neuroinflammatory factors in stress- and drug-induced reinstatement of methamphetamine in extinguished rats. Addict Biol 25:e12740. https://doi.org/10.1111/adb.12740

Karimi-Haghighi S, Haghparast A (2018) Cannabidiol inhibits priming-induced reinstatement of methamphetamine in REM sleep deprived rats. Prog Neuropsychopharmacol Biol Psychiatry 82:307-313. https://doi.org/10.1016/j.pnpbp.2017.08.022

Kenny PJ, Koob GF, Markou A (2003) Conditioned facilitation of brain reward function after repeated cocaine administration. Behav Neurosci 117:1103-1107. https://doi.org/10.1037/0735-7044. 117.5.1103

Knapp WP, Soares B, Farrell M, Silva de Lima M (2007) Psychosocial interventions for cocaine and psychostimulant amphetamines related disorders. Cochrane Database Syst Rev. https://doi.org/ 10.1002/14651858.CD003023.pub2

Kogan NM, Mechoulam R (2007) Cannabinoids in health and disease. Dialogues Clin Neurosci 9:413-430. https://doi.org/10.31887/ DCNS.2007.9.4/nkogan

Kruk-Slomka M, Dzik A, Budzynska B, Biala G (2017) Endocannabinoid system: the direct and indirect involvement in the memory and learning processes - A short review. Mol Neurobiol 54:83328347. https://doi.org/10.1007/s12035-016-0313-5

Kuhn BN, Kalivas PW, Bobadilla A-C (2019) Understanding addiction using animal models. Frontiers in Behavioral Neuroscience 13. https://doi.org/10.3389/fnbeh.2019.00262

Lake CR, Quirk RS (1984) CNS stimulants and the look-alike drugs. Psychiatr Clin North Am 7:689-701

Lamarque S, Taghzouti K, Simon H (2001) Chronic treatment with $\Delta^{9}$-tretrahydrocannabinol enhances the locomotor response to amphetamine and heroin. Implications for vulnerability to drug addiction. Neuropharmacology 41:118-129. https://doi.org/10. 1016/S0028-3908(01)00039-9

Laprairie RB, Bagher AM, Kelly ME, Denovan-Wright EM (2015) Cannabidiol is a negative allosteric modulator of the cannabinoid CB1 receptor. Br J Pharmacol 172:4790-4805. https://doi.org/ 10.1111/bph. 13250

Lau N, Sales P, Averill S, Murphy F, Sato S-O, Murphy S (2015) A safer alternative: cannabis substitution as harm reduction. Drug Alcohol Rev 34:654-659. https://doi.org/10.1111/dar.12275

Lee NK, Rawson RA (2008) A systematic review of cognitive and behavioural therapies for methamphetamine dependence. Drug Alcohol Rev 27:309-317. https://doi.org/10.1080/0959523080 1919494 
Lu H-C, Mackie K (2021) Review of the endocannabinoid system. Biol Psychiat Cogn Neurosci Neuroimag 6:607-615. https://doi.org/ 10.1016/j.bpsc.2020.07.016

Lucas P, Reiman A, Earleywine M, McGowan SK, Oleson M, Coward MP, Thomas B (2013) Cannabis as a substitute for alcohol and other drugs: a dispensary-based survey of substitution effect in Canadian medical cannabis patients. Addict Res Theory 21:435442. https://doi.org/10.3109/16066359.2012.733465

Maldonado R, Valverde O, Berrendero F (2006) Involvement of the endocannabinoid system in drug addiction. Trends Neurosci 29:225-232. https://doi.org/10.1016/j.tins.2006.01.008

Manzanares J, Cabañero D, Puente N, García-Gutiérrez MS, Grandes P, Maldonado R (2018) Role of the endocannabinoid system in drug addiction. Biochem Pharmacol 157:108-121. https://doi. org/10.1016/j.bcp.2018.09.013

Marcu J (2020) The legalization of cannabinoid products and standardizing cannabis-drug development in the United States: a brief report. Dialogues Clin Neurosci 22:289-293. https://doi.org/10. 31887/DCNS.2020.22.3/jmarcu

Marshall BD, Werb D (2010) Health outcomes associated with methamphetamine use among young people: a systematic review. Addiction 105:991-1002. https://doi.org/10.1111/j.1360-0443. 2010.02932.x

Marshall BDL, Galea S, Wood E, Kerr T (2011) Injection methamphetamine use is associated with an increased risk of attempted suicide: a prospective cohort study. Drug Alcohol Depend 119:134-137. https://doi.org/10.1016/j.drugalcdep.2011.05.012

McGowan J, Sampson M, Salzwedel DM, Cogo E, Foerster V, Lefebvre C (2016) PRESS Peer Review of Electronic Search Strategies: 2015 guideline statement. J Clin Epidemiol 75:40-46. https:// doi.org/10.1016/j.jclinepi.2016.01.021

McKetin R et al (2019) Mental health outcomes associated with the use of amphetamines: A systematic review and meta-analysis. E Clinical Medicine 16:81-97. https://doi.org/10.1016/j.eclinm. 2019.09.014

McKetin R, Lubman DI, Baker AL, Dawe S, Ali RL (2013) Doserelated psychotic symptoms in chronic methamphetamine users: evidence from a prospective longitudinal study. JAMA Psychiat 70:319-324. https://doi.org/10.1001/jamapsychiatry.2013.283

Mechoulam R, Parker LA (2013) The endocannabinoid system and the brain. Annu Rev Psychol 64:21-47. https://doi.org/10.1146/ annurev-psych-113011-143739

Meneses-Gaya CD et al (2020) Cannabidiol for the treatment of crackcocaine craving: An exploratory double-blind study. Brazil J Psychiat. https://doi.org/10.1590/1516-4446-2020-1416

Minozzi S, Saulle R, De Crescenzo F, Amato L (2016) Psychosocial interventions for psychostimulant misuse. Cochrane Datab Syst Rev 9:Cd011866. https://doi.org/10.1002/14651858.CD011866. pub2

Mongeau-Pérusse V et al (2021) Cannabidiol as a treatment for craving and relapse in individuals with cocaine use disorder: a randomized placebo-controlled trial. Addiction. https://doi.org/10. 1111/add. 15417

Moreira FA, Guimarães FS (2005) Cannabidiol inhibits the hyperlocomotion induced by psychotomimetic drugs in mice. Eur $\mathbf{J}$ Pharmacol 512:199-205. https://doi.org/10.1016/j.ejphar.2005. 02.040

Morgan CJA, Das RK, Joye A, Curran HV, Kamboj SK (2013) Cannabidiol reduces cigarette consumption in tobacco smokers: preliminary findings. Addict Behav 38:2433-2436. https://doi.org/ 10.1016/j.addbeh.2013.03.011

Morley KC, Cornish JL, Faingold A, Wood K, Haber PS (2017) Pharmacotherapeutic agents in the treatment of methamphetamine dependence. Expert Opin Investig Drugs 26:563-578. https:// doi.org/10.1080/13543784.2017.1313229
Müller CP, Homberg JR (2015) The role of serotonin in drug use and addiction. Behav Brain Res 277:146-192. https://doi.org/10. 1016/j.bbr.2014.04.007

NASEM (2017) The health effects of cannabis and cannabinoids: the current state of evidence and recommendations for research. The National Academies Press, Washington, DC. https://doi.org/10. $17226 / 24625$

O'Brien CP, Childress AR, Ehrman R, Robbins SJ (1998) Conditioning factors in drug abuse: Can they explain compulsion? J Psychopharmacol 12:15-22. https://doi.org/10.1177/026988119801200 103

Parker LA, Burton P, Sorge RE, Yakiwchuk C, Mechoulam R (2004) Effect of low doses of delta9-tetrahydrocannabinol and cannabidiol on the extinction of cocaine-induced and amphetamine-induced conditioned place preference learning in rats. Psychopharmacology 175:360-366. https://doi.org/10.1007/ s00213-004-1825-7

Parsons LH, Hurd YL (2015) Endocannabinoid signalling in reward and addiction. Nat Rev Neurosci 16:579-594. https://doi.org/10. $1038 /$ nrn 4004

Patton MQ (2015) Qualitative research \& evaluation methods: integrating theory and practice. 4 edn. Sage/Learning Matters, Thousand Oaks

Paul B, Thulien M, Knight R, Milloy MJ, Howard B, Nelson S, Fast D (2020) "Something that actually works": cannabis use among young people in the context of street entrenchment. PloS one 15:e236243. https://doi.org/10.1371/journal.pone.0236243

Peacock A et al (2018) Global statistics on alcohol, tobacco and illicit drug use: 2017 status report. Addiction 113:1905-1926. https:// doi.org/10.1111/add.14234

Pedrazzi JF, Issy AC, Gomes FV, Guimarães FS, Del-Bel EA (2015) Cannabidiol effects in the prepulse inhibition disruption induced by amphetamine. Psychopharmacology 232:3057-3065. https:// doi.org/10.1007/s00213-015-3945-7

Pelloux Y, Giorla E, Montanari C, Baunez C (2019) Social modulation of drug use and drug addiction. Neuropharmacology 159:107545. https://doi.org/10.1016/j.neuropharm.2019.02.027

Pérez-Mañá C, Castells X, Torrens M, Capellà D, Farre M (2013) Efficacy of psychostimulant drugs for amphetamine abuse or dependence. Cochrane Database Syst Rev. https://doi.org/10. 1002/14651858.CD009695.pub2

Prud'homme M, Cata R, Jutras-Aswad D (2015) Cannabidiol as an intervention for addictive behaviors: A systematic review of the evidence. Subst Abuse 9:33-38. https://doi.org/10.4137/sart. S25081

Rathbone J, Carter M, Hoffmann T, Glasziou P (2015) Better duplicate detection for systematic reviewers: evaluation of systematic review assistant-deduplication Module. Syst Rev 4:6. https://doi. org/10.1186/2046-4053-4-6

Razavi Y, Shabani R, Mehdizadeh M, Haghparast A (2020) Neuroprotective effect of chronic administration of cannabidiol during the abstinence period on methamphetamine-induced impairment of recognition memory in the rats. Behav Pharmacol 31:385-396. https://doi.org/10.1097/fbp.0000000000000544

Renard J et al (2016) Cannabidiol counteracts amphetamine-induced neuronal and behavioral sensitization of the mesolimbic dopamine pathway through a novel mTOR/p70S6 kinase signaling pathway. J Neurosci 36:5160-5169. https://doi.org/10.1523/jneur osci.3387-15.2016

Ronsley C et al (2020) Treatment of stimulant use disorder: a systematic review of reviews. PloS one 15:e0234809. https://doi.org/10. 1371/journal.pone.0234809

Shearer J (2007) Psychosocial approaches to psychostimulant dependence: a systematic review. J Subst Abuse Treat 32:41-52. https:// doi.org/10.1016/j.jsat.2006.06.012 
Shorter D, Domingo CB, Kosten TR (2015) Emerging drugs for the treatment of cocaine use disorder: a review of neurobiological targets and pharmacotherapy. Expert Opin Emerg Drugs 20:1529. https://doi.org/10.1517/14728214.2015.985203

Siefried KJ, Acheson LS, Lintzeris N, Ezard N (2020) Pharmacological treatment of methamphetamine/amphetamine dependence: a systematic review. CNS Drugs 34:337-365. https://doi.org/10. 1007/s40263-020-00711-x

Simons JS, Dvorak RD, Batien BD (2008) Methamphetamine use in a rural college population: associations with marijuana use, sensitivity to punishment, and sensitivity to reward. Psychol Addict Behav 22:444-449. https://doi.org/10.1037/0893-164x. 22.3.444

Socías ME et al (2017) Intentional cannabis use to reduce crack cocaine use in a Canadian setting: a longitudinal analysis. Addict Behav 72:138-143. https://doi.org/10.1016/j.addbeh.2017.04.006

Spanagel R (2017) Animal models of addiction. Dialogues Clin Neurosci 19:247-258. https://doi.org/10.31887/DCNS.2017.19.3/ rspanagel

Spanagel R (2020) Cannabinoids and the endocannabinoid system in reward processing and addiction: from mechanisms to interventions. Dialogues Clin Neurosci 22:241-250. https://doi.org/10. 31887/DCNS.2020.22.3/rspanagel

Strakowski SM, Sax KW (1998) Progressive behavioral response to repeated d-amphetamine challenge: further evidence for sensitization in humans. Biol Psychiat 44:1171-1177. https://doi.org/ 10.1016/s0006-3223(97)00454-x

Strickland JC, Havens JR, Stoops WW (2019) A nationally representative analysis of "twin epidemics": rising rates of methamphetamine use among persons who use opioids. Drug Alcohol Depend 204:107592. https://doi.org/10.1016/j.drugalcdep.2019.107592

Sung YH, Carey PD, Stein DJ, Ferrett HL, Spottiswoode BS, Renshaw PF, Yurgelun-Todd DA (2013) Decreased frontal N-acetylaspartate levels in adolescents concurrently using both methamphetamine and marijuana. Behav Brain Res 246:154-161. https://doi. org/10.1016/j.bbr.2013.02.028
Tardelli VS, Bisaga A, Arcadepani FB, Gerra G, Levin FR, Fidalgo TM (2020) Prescription psychostimulants for the treatment of stimulant use disorder: A systematic review and meta-analysis. Psychopharmacology 237:2233-2255. https://doi.org/10.1007/ s00213-020-05563-3

Turna J, Syan SK, Frey BN, Rush B, Costello MJ, Weiss M, MacKillop J (2019) Cannabidiol as a novel candidate alcohol use disorder pharmacotherapy: a systematic review. Alcoholism: Clinical and Experimental Research 43:550-563 doi:https://doi.org/10.1111/acer.13964

UNODC (2020) World Drug Report 2020. United Nations Publication.

Valvassori SS et al (2011) Effects of cannabidiol on amphetamineinduced oxidative stress generation in an animal model of mania. J Psychopharmacol 25:274-280. https://doi.org/10.1177/02698 81109106925

Voytek B et al (2005) Differences in regional brain metabolism associated with marijuana abuse in methamphetamine abusers. Synapse 57:113-115. https://doi.org/10.1002/syn.20155

Wood E, Stoltz J-A, Montaner JSG, Kerr T (2006) Evaluating methamphetamine use and risks of injection initiation among street youth: The ARYS study. Harm Reduct J 3:18. https://doi.org/10. 1186/1477-7517-3-18

Yang $\mathrm{G}$ et al (2020) Cannabidiol attenuates methamphetamine-induced conditioned place preference via the Sigma1R/AKT/GSK-3 $\beta /$ CREB signaling pathway in rats. Toxicology Research 9:202211. https://doi.org/10.1093/toxres/tfaa021

Yockey RA, King KA, Vidourek RA (2020) Past-year methamphetamine use among US young adults: 2015-2018. Journal of Substance Use 25:677-682. https://doi.org/10.1080/14659891.2020. 1760380

Young JW, Henry BL, Geyer MA (2011) Predictive animal models of mania: Hits, misses and future directions. Br J Pharmacol 164:1263-1284. https://doi.org/10.1111/j.1476-5381.2011. 01318.x

Publisher's note Springer Nature remains neutral with regard to jurisdictional claims in published maps and institutional affiliations.

\section{Authors and Affiliations}

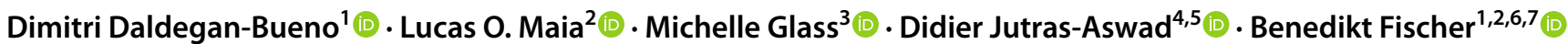

1 Schools of Population Health and Pharmacy, Faculty of Medical and Health Sciences, University of Auckland, 85 Park Rd, Grafton, Auckland 1023, New Zealand

2 Centre for Applied Research in Mental Health \& Addiction, Simon Fraser University, 515 W. Hastings Street, Vancouver, BC V6B 5K3, Canada

3 Department of Pharmacology and Toxicology, University of Otago, PO Box 56, Dunedin 9054, Otago, New Zealand

4 Centre de Recherche, Centre Hospitalier Universitaire de Universite de Montreal (CHUM), 1051 Rue Sanguinet, Montréal, QC H2X 3E4, Canada
5 Department of Psychiatry and Addiction, Faculty of Medicine, Université de Montréal, Pavillon Roger-Gaudry, 2900 Edouard Montpetit Blvd, Montreal, QC H3T 1J4, Canada

6 Department of Psychiatry, University of Toronto, 250 College Street, 8Th Floor, Toronto, ON M5T 1R8, Canada

7 Department of Psychiatry, Federal University of Sao Paulo (UNIFESP), R. Dr. Ovídio Pires de Campos, Sao Paulo 785 05403-903, Brazil 